\title{
CORROSÃO SOB TENSÃO EM SOLDA CIRCUNFERENCIAL DE AÇO API 5L X70 EM CONTATO COM ETANOL
}

\author{
Vinícius Girogetti ' \\ Javier Alejandro Carreno Velasco ${ }^{2}$ \\ Rodrigo Vieira Landim ${ }^{2}$ \\ Vitor Luiz Sordi ${ }^{\prime}$
}

\section{Resumo}

As juntas de solda de campo circunferenciais usadas na construção de dutos para transporte de petróleo e derivados constituem regiões susceptíveis a defeitos que podem levar a falhas em operação. Neste trabalho uma junta circunferencial de um duto de aço API $5 L$ X70 foi produzida em laboratório e avaliada por meio de ensaios de dureza, tração e impacto; a corrosão sob tensão promovida pela exposição ao etanol combustível foi avaliada em ensaios de tração com baixa taxa de deformação em corpos de prova com entalhes posicionados nas distintas regiões da solda; as microestruturas do material de base e da região soldada foram caracterizadas por microscopia ótica e as superfícies fraturadas foram analisadas ao MEV. A análise da fratura após em ensaios de tração e de impacto indicou que as descontinuidades da solda, ainda que qualificada, interferem significativamente no mecanismo de fratura, tendendo à fragilização, especialmente nos testes de impacto. A susceptibilidade à corrosão sob tensão ficou evidente, tanto na zona termicamente afetada quanto no metal de solda, promovendo perda de ductilidade e acelerando o processo de fratura nos ensaios de baixa taxa de deformação em presença de etanol.

Palavras-chave: Duto; Solda circunferencial; Corrosão sob tensão; Etanol; Tubo API 5L X70

\section{STRESS CORROSION CRACKING OF CIRCUMFERENTIAL WELDING JOINT IN API 5L X70 LINE PIPE IN ETHANOL ENVIRONMENT}

\begin{abstract}
s
Circumferential field-welding joints of oil pipelines are susceptible to defects that may lead to failures when in operation. In this work a circumferential joint of an API $5 \mathrm{~L}$ X70 line pipe was produced in a laboratory and evaluated by hardness, tensile and impact tests; stress corrosion cracking promoted by exposition to fuel ethanol was evaluated by slow strain rate tensile tests using notched specimens; the micro-structures were characterized by optical microscopy in the different regions of the welded joint and the fractured surfaces were analyzed by SEM. The fracture surface of the welding metal after tensile and impact tests indicated that the presence of welding discontinuities may strongly affect the fracture behavior, leading to embrittlement, especially in the impact tests. Stress corrosion cracking occurred in both evaluated regions (welding metal and heat affected zone) of the welds when subjected to slow strain rate tensile tests in contact with ethanol.
\end{abstract}

Keywords: Pipeline; Circunferencial weld; Stress corrosion cracking; Ethanol; Tube API 5L X70.

\section{INTRODUÇÃO}

Os dutos utilizados para o transporte de petróleo e derivados em longas distâncias são formados pela ligação soldada entre tubos fabricados com aços classificados pela norma API $5 \mathrm{~L}[\mathrm{I}]$. O movimento dos produtos se dá por pressão, ocasionando tensões circunferenciais e longitudinais em suas paredes. $O$ produto a ser transportado também pode interagir com as paredes do tubo, especialmente nas juntas soldadas onde trincas podem se originar em pontos de concentração de tensões. $O$ fenômeno da corrosão sob tensão (CST) tem sido observado em soldas expostas ao etanol combustível e sujeitas a altas tensões e esforços cíclicos [2]. Entretanto, a estimativa da vida em serviço desses

'Departamento de Engenharia de Materiais, Universidade Federal de São Carlos - UFSCar, São Carlos, SP, Brasil. E-mail: viniciusgiorgetti@yahoo.com.br ${ }^{2}$ Laboratório LAH2S, Instituto Nacional de Tecnologia - INT, Rio de Janeiro, RJ,Brasil

2176-1523 (C) 2019 Associação Brasileira de Metalurgia, Materiais e Mineração. Publicado pela ABM. Este é um artigo de acesso aberto distribuído sob os termos da licença Creative Commons CC BY-NC-ND (Attribution-NonCommercial-NoDerivs) - https:// creativecommons.org/licenses/by-nc-nd/4.0\%. 
componentes constitui uma tarefa complexa, considerando a heterogeneidade de propriedades nas regiões soldadas, a distribuição não uniforme de tensões, e a variedade de composições possíveis do etanol combustível. $\mathrm{O}$ objetivo deste trabalho foi avaliar a região da junta circunferencial em termos da microestrutura, da distribuição da dureza na região soldada e da resistência à tração, e ao impacto. Essa caracterização é uma base fundamental necessária ao estudo dos efeitos da interação material-meio nas propriedades da junta, com vistas à avaliação da integridade do duto em serviço. Neste sentido, ensaios de tração com baixa taxa de deformação (TBTD) em meio etanol foram realizados para avaliar a ocorrência de CST no metal de solda (MS) e na zona termicamente afetada (ZTA).

\section{MATERIAIS E MÉTODOS}

Um tubo de aço API 5L X70, com 24 pol. ( 610 mm) de diâmetro e $21 \mathrm{~mm}$ de espessura de parede foi soldado circunferencialmente, utilizando-se chanfro em $1 / 2 \mathrm{~V}$ e procedimento idêntico ao utilizado em campo na construção dos dutos, atendendo a norma API I I 04 [3]. A solda de raiz foi feita com TIG, eletrodo ER70S-3 e a solda de enchimento com eletrodo revestido $E$ - 80 I0G. A composição química do metal de base(MB), determinada por espectrometria ótica, está mostrada na Tabela I. A microestrutura foi observada por microscopia ótica (MO) nos planos $S$, $T$ e $L$, os quais se encontram indicados na Figura la em relação à chapa de fabricação do tubo. No MS e na ZTA a microestrutura foi observada no plano T. A microdureza Vickers foi mapeada sobre uma secção da junta soldada, no mesmo plano T, com cerca de setecentas impressões espaçadas de I mm, utilizando carga de $100 \mathrm{gf} / \mathrm{I} 5 \mathrm{~s}$ e adotando-se o procedimento definido pela norma ASTM E384 [4]. Ensaios de tração convencional seguiram a norma ASTM E8M [5], utilizando corpos de prova
(CP) cilíndricos com diâmetro de $8 \mathrm{~mm}$ e comprimento de referência igual a $40 \mathrm{~mm}$, extraídos do $\mathrm{MB}$ nas direções circunferencial $(C)$ e longitudinal $(L)$ do tubo e também na região da solda (S), conforme a Figura Ib. Os ensaios foram realizados em duplicata numa máquina de ensaios INSTRON 5500 , com taxa de deformação inicial igual a $1 \times 10^{-3} \mathrm{~s}^{-1}$. Para os ensaios TBTD, a taxa de deformação foi igual a $|\times| 0^{-6}$ $\mathrm{s}^{-1}$, usando-se $C P^{\prime}$ s cilíndricos, com entalhe circular em $\mathrm{V}$, conforme norma NACE TMO I I I [6], imersos numa solução sintética de etanol combustível (SFGE - Syntheticfuel grade ethanol) nos limites máximos de impurezas da norma ASTM D4806 [7]. Ensaios de impacto Charpy foram realizados ao ar, em temperatura ambiente, usando CP's padronizados conforme ASTM E23 [8], com os entalhes posicionados no $M B$, no $M S$ e na ZTA, na orientação L-S, i.e., de modo a propagar a fratura desde parede interna para a externa do tubo. $O$ caminho da fratura em relação às interfaces MS/ZTA/MB foi observado por meio de macrografias e as superfícies fraturadas foram observadas ao microscópio eletrônico de varredura (MEV).

\section{RESULTADOS}

\section{I Microestruturas da Junta Soldada}

Sabe-se que a adição de elementos de liga e o controle dos parâmetros de processamento termomecânico são os fatores determinantes na microestrutura e nas decorrentes propriedades mecânicas dos aços API $[9,10]$. A Figura 2 apresenta as microestruturas características do MB nos planos S, T e L, que são constituídas essencialmente por matriz ferrítica de diferentes formas (áreas claras) e perlita fina (áreas escuras), com grãos finos e alongados no sentido da laminação. No plano T (Figura $2 b$ ) o alongamento da ferrita na direção de laminação é claramente visível, assim

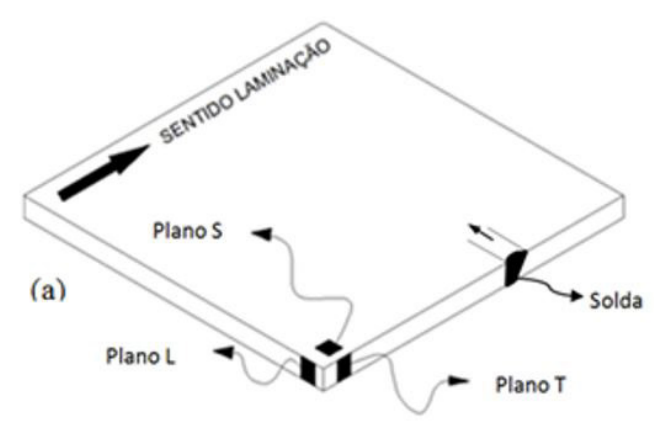

(b)

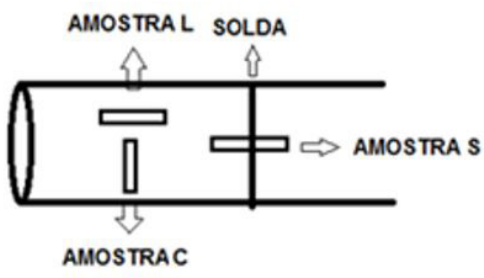

Figura I. (a) Planos de observação metalográfica e direção da solda circunferencial em relação à chapa original de fabricação do tubo; (b) extração dos corpos de prova do tubo para ensaios de tração e de CST.

Tabela I. Composição química do material do tubo

\begin{tabular}{|c|c|c|c|c|c|c|c|c|c|c|c|c|c|c|}
\hline Elem. & C & Si & Mn & $\mathbf{P}$ & $\mathrm{Cu}$ & Mo & $\mathbf{N i}$ & V & $\mathbf{T i}$ & $\mathbf{N b}$ & Co & $\mathbf{W}$ & $\mathbf{S}$ & $\mathrm{Ceq}$ \\
\hline $\begin{array}{c}\% \\
\text { (peso) }\end{array}$ & 0,07 & 0,22 & $\mathrm{I}, 87$ & 0,025 & 0,16 & 0,02 & 0,12 & 0,05 & 0,016 & 0,06 & 0,022 & 0,075 & 0,02 & 0,41 \\
\hline
\end{tabular}


como o bandeamento em regiões de ferrita e perlita fina. Detalhes da microestrutura perlítica, observada ao MEV, podem ser vistos na Figura 2c. No plano S, o bandeamento da estrutura não ficou tão evidente e as regióes de perlita (escuras) aparecem de forma mais ou menos heterogênea entre as de ferrita (claras). No plano L, perpendicular à direção de laminação, os grãos tem aparência equiaxial e o bandeamento em camadas de perlita fina e ferrita poligonal se distribui regularmente ao longo da secção.

$\mathrm{Na}$ Figura 3 evidenciam-se as diferentes microestruturas em um corte transversal (plano T) do cordão de solda. Note-se o chanfro "meio V", com o qual se pretendeu obter uma região de ZTA mais regular em um dos lados. As regiões $2 \mathrm{a}$ e 3 a mostram uma microestrutura parcialmente recristalizada, constituída predominantemente por grãos de ferrita poligonal e perlita dispersa nos contornos. Esta é referida como região recristalizada de granulação grosseira [I I], já com alguma uma tendência de crescimento dos grãos, em decorrência dos sucessivos reaquecimentos durante a soldagem. Na região la, que sofreu menor aporte térmico e resfriamento mais rápido, ainda há sinais do bandeamento da microestrutura original, mas com grãos mais finos e menos alongados, indicando que houve recristalização. Na região da raiz, 4a, a microestrutura mais grosseira sugere que houve fusão do MB. No lado do MS, a regiãol apresenta predominantemente grãos de ferrita de Widmanstatten com presença de perlita dispersa, características do resfriamento mais rápido após o último passe. As regiões intermediárias ( 2 s e $3 \mathrm{~s}$ ) apresentam grãos de ferrita poligonal com presença de perlita em seus contornos. A microestrutura na raiz, $4 \mathrm{~s}$, é constituída de grãos grosseiros de ferrita poligonal com perlita concentrada nos contornos. Esta região, sujeita ao procedimento diferenciado de soldagem e a sucessivos ciclos térmicos, corresponde à região de menor dureza mostrada no mapeamento da dureza Vickers, na parte superior direita da Figura 3. O mapa revela também a dureza (a)

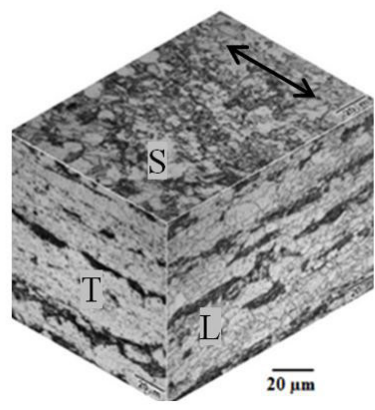

(b)

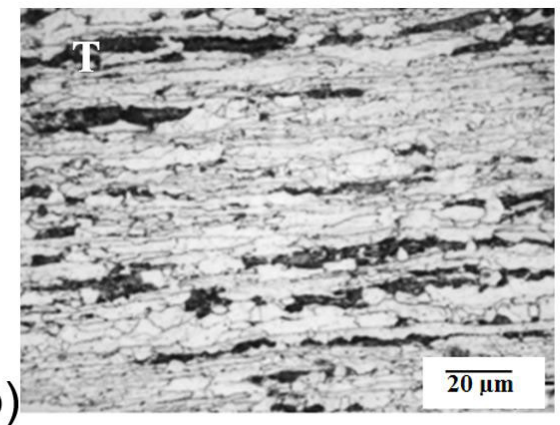

(c)

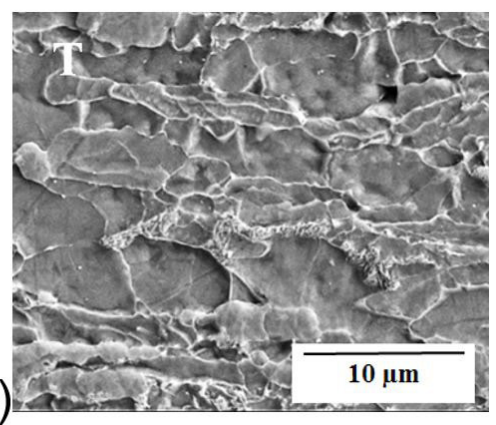

Figura 2. Planos S, L e T e seta indicando a direção de laminação do MB (a); ampliação do plano T por MO (b) e por MEV (c).

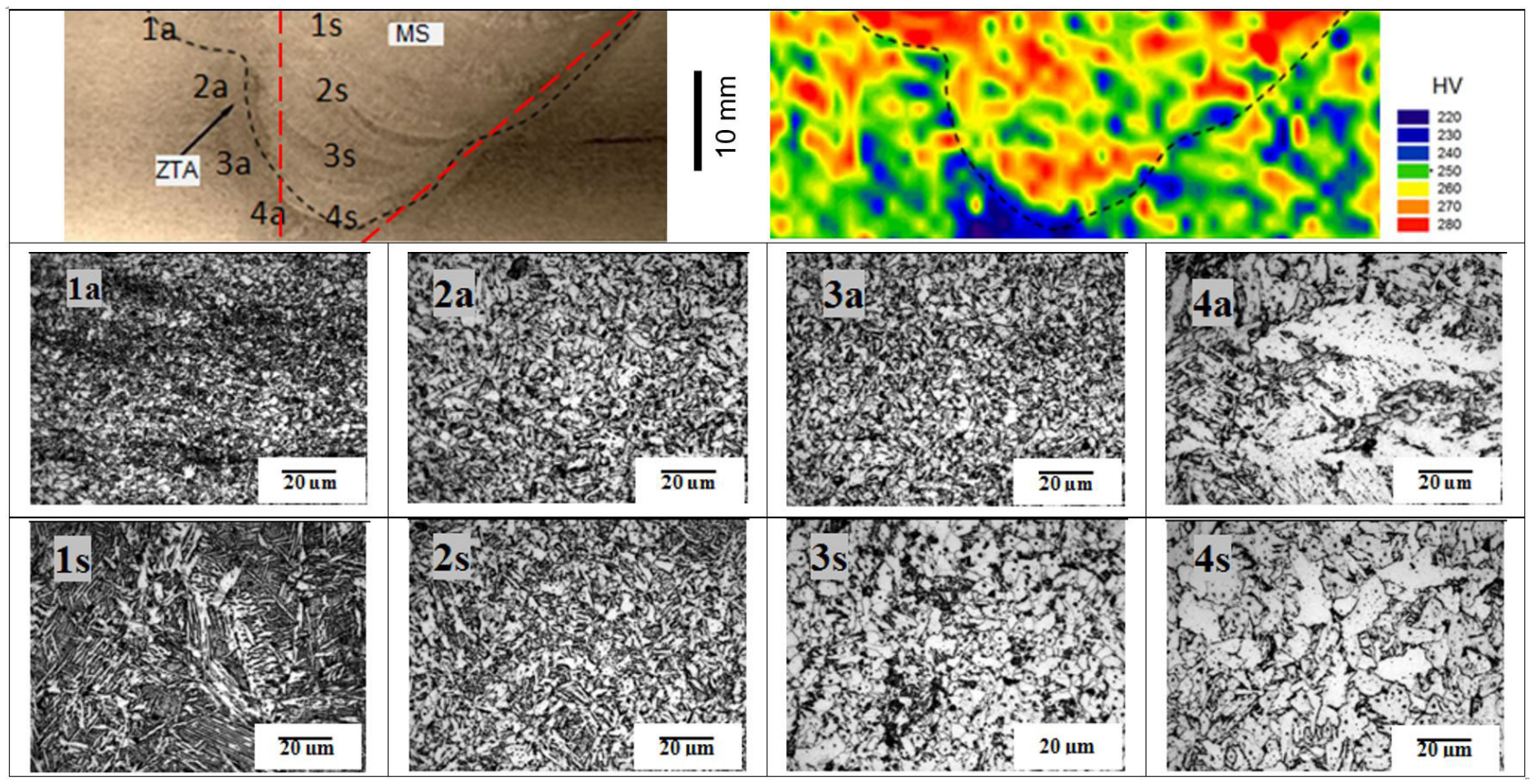

Figura 3. Mapeamento da dureza numa secção transversal do cordão de solda e microestruturas típicas da ZTA (la, 2a, 3a, 4a) e do $\mathrm{MS}(\mathrm{Is}, 2 \mathrm{~s}, 3 \mathrm{~s}, 4 \mathrm{~s})$. 
média do MS ( $\sim 270 \mathrm{HV})$, um pouco maior que a do MB, e algumas regióes mais duras $(\sim 280 \mathrm{HV})$ nos passes finais do processo de soldagem.

\subsection{Resistência à Tração e Corrosão sob Tensão}

Com os resultados da análise química e com os valores obtidos nos ensaios de tração (limite de escoamento, LE, maior que $483 \mathrm{MPa}$; limite de resistência à tração, $L R$, maior que $565 \mathrm{MPa}$ e LE/LR menor que 0,93) o MB atendeu às exigências de classificação do aço API $5 \mathrm{~L}$ X70 [ $\mathrm{I}$. Nas curvas da Figura 4 se vê que na direção circunferencial (MB-C) a resistência é um pouco maior que na longitudinal (MB-L). A anisotropia é esperada devido à microestrutura bandeada, já relatada, e os valores são compatíveis com os obtidos em outros trabalhos [12-14]. Os CP's que continham uma porção soldada (MS) romperam na solda, mas mesmo assim alcançaram os limites mínimos da categoria X70 [I]. A perda de ductilidade foi atribuída à presença de descontinuidades no $\mathrm{MS}$, conforme será observado na análise da fratura.
A parte superior direita da Figura 4 apresenta a superfície de fratura de um corpo de prova MB-C com aspecto de fratura dúctil assistida pelo micromecanismo de coalescência das microcavidades ("dimples”), as quais envolvem inclusões dispersas no interior da matriz metálica. Nota-se também os aspecto ovalizado da seção na fratura e evidências de delaminação, consequências da microestrutura bandeada e da alta densidade de grãos alongados do $\mathrm{MB}$, já mostrados na Figura 2. O corpo de prova MB-L (não mostrado) apresentou comportamento similar, com fratura dúctil e evidências de delaminações e fissuras perpendiculares ao plano da fratura. Quanto ao CP MS, na parte inferior direita da Figura 4, se observa a baixa redução de área e topografia irregular da fratura, com algumas visíveis descontinuidades na solda, ao que se atribuiu a redução do alongamento final. Em comparação com o MB-C os alvéolos são menores e o nível de deformação plástica é bem menor.

$\mathrm{Na}$ Figura 5 são apresentadas as curvas obtidas em ensaios de TBDT, ao ar e em etanol (SFGE), utilizando corpos de prova com entalhe circunferencial posicionado numa região de MS ou de ZTA, no centro do CP. Os ensaios ao

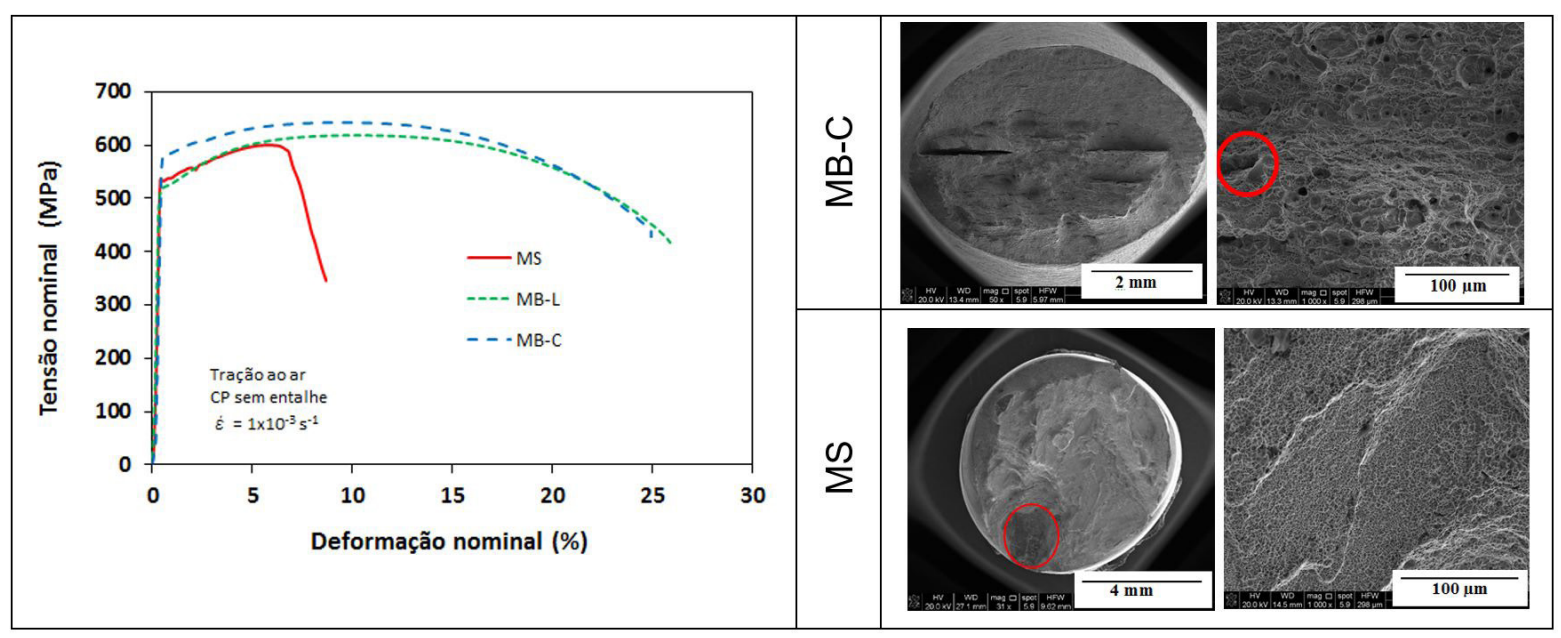

Figura 4. Curvas tensão-deformação e aspectos da fratura em corpo de prova com solda na parte central do comprimento (MS) ou inteiramente de MB extraído nas direções L e C (Ver Figura Ib).
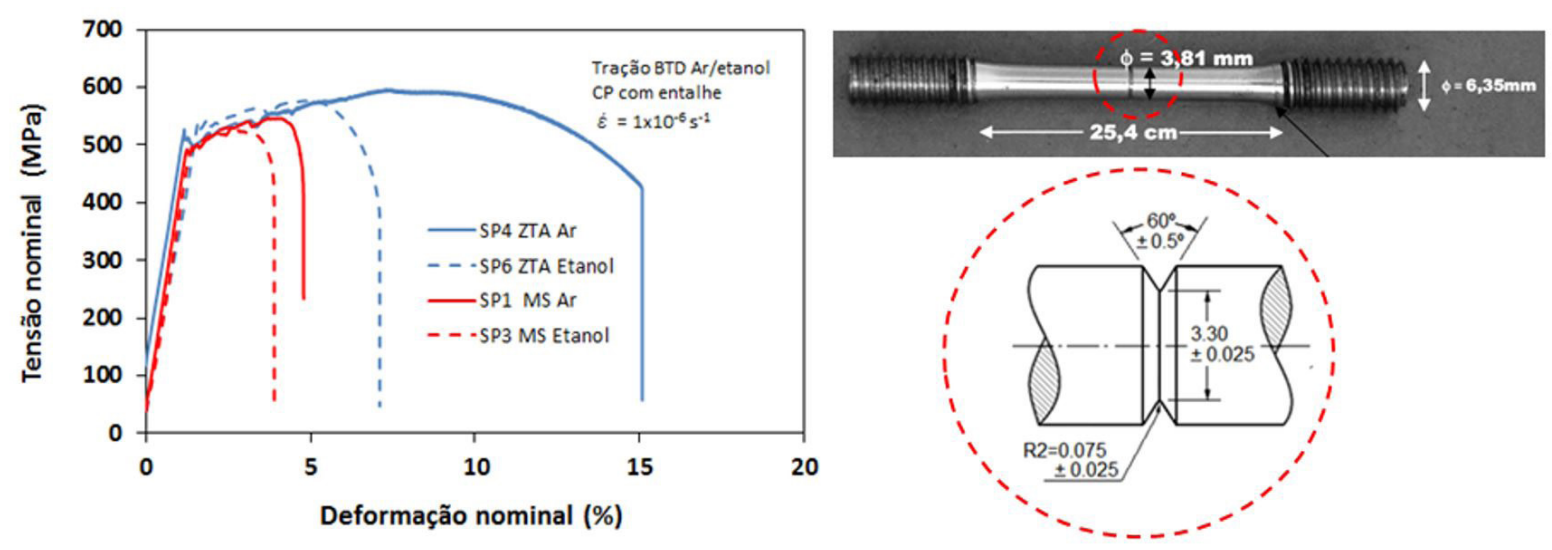

Figura 5. Ensaios de TBTD ao ar e em etanol, em corpos de prova com entalhe posicionado na ZTA ou no MS. Geometria do entalhe, conforme NACE TMOIII [6]. 
ar romperam fora do entalhe, como esperado na ausência de CST, e apresentaram alongamentos maiores que seus pares em etanol. Por outro lado, na presença de etanol a fratura ocorreu no entalhe, tanto para ZTA quanto MS, com perda de ductilidade (menor alongamento) e sinais evidentes de CST na superfície de fratura. Note-se que as baixas velocidades de deformação têm como finalidade dar tempo para que os processos de corrosão possam progredir na ponta do entalhe. No caso da ZTA, o tempo total de duração do teste foi drasticamente reduzido, de $\sim 42 \mathrm{~h}$ para $\sim 19 \mathrm{~h}$, devido à perda de ductilidade causada pela CST. No MS o efeito foi menos visível devido às descontinuidades da microestrutura, mas também houve redução (de 16\%) no tempo de ensaio.

Na Figura 6, as superfícies de fratura evidenciam região em forma de anel externo, a partir da ponta do entalhe, típica de fratura frágil promovida por CST; região intermediária de transição para fratura por cisalhamento e região central com fratura dúctil, onde predominam a formação e coalescência de microcavidades. $O$ entalhe na ZTA fez com que a região central da fratura apresentasse morfologia alveolar típica dessas microcavidades, indicando fratura por sobretensão; no caso do MS a fratura final também tem aspecto dúctil, mas com os alvéolos bem menores, alternando algumas áreas de fratura mais frágil produzida pelo mecanismo de clivagem. Além disso, ficou evidente uma descontinuidade da solda, tipo de evento que também se observou na amostra ensaiada ao ar (MS-Ar), e que certamente contribuiu para a redução do alongamento final nos corpos de prova com solda. Nos dois casos (ZTA e MS), a presença do etanol afetou sensivelmente o processo de fratura.

\subsection{Fratura por Impacto na Junta Soldada}

Ensaios de impacto Charpy foram realizados em corpos de prova com o entalhe posicionado nas regiões de MB, MS e ZTA. As Figuras 7a e 7b mostram macrografias da seção longitudinal da fratura para entalhes na ZTA, evidenciando que o caminho de propagação da fratura tendeu a se desviar para a interface ZTA/MS (Figura 7a) ou para a interface ZTA/MB (Figura 7b). No caso do entalhe posicionado no MS (Figura 7c) fica evidente que o caminho da fratura é afetado pelas descontinuidades da solda, desviando o plano de propagação para as interfaces entre os passes de solda sobrepostos, tendendo a fragilizar a fratura e a diminuir a energia absorvida $(E)$, cujos valores estão mostrados na mesma figura. Com o entalhe posicionado no $M B$ os valores de $E$ se repetiram bem nas tréplicas ensaiadas, e foram bem maiores $(\sim 3$ vezes) que os encontrados com entalhe e fratura no MS. Os valores de E do metal de base estão compatíveis com os normalmente encontrados para essa classe de material, porém sabe-se a orientação do entalhe (plano de propagação da fratura) pode afetar sensivelmente o valor da energia absorvida $[15,16]$. No presente caso, os entalhes foram posicionados na orientação L-S em relação à laminação da chapa original (ver Figura la), o que corresponde à propagação da fratura do interior

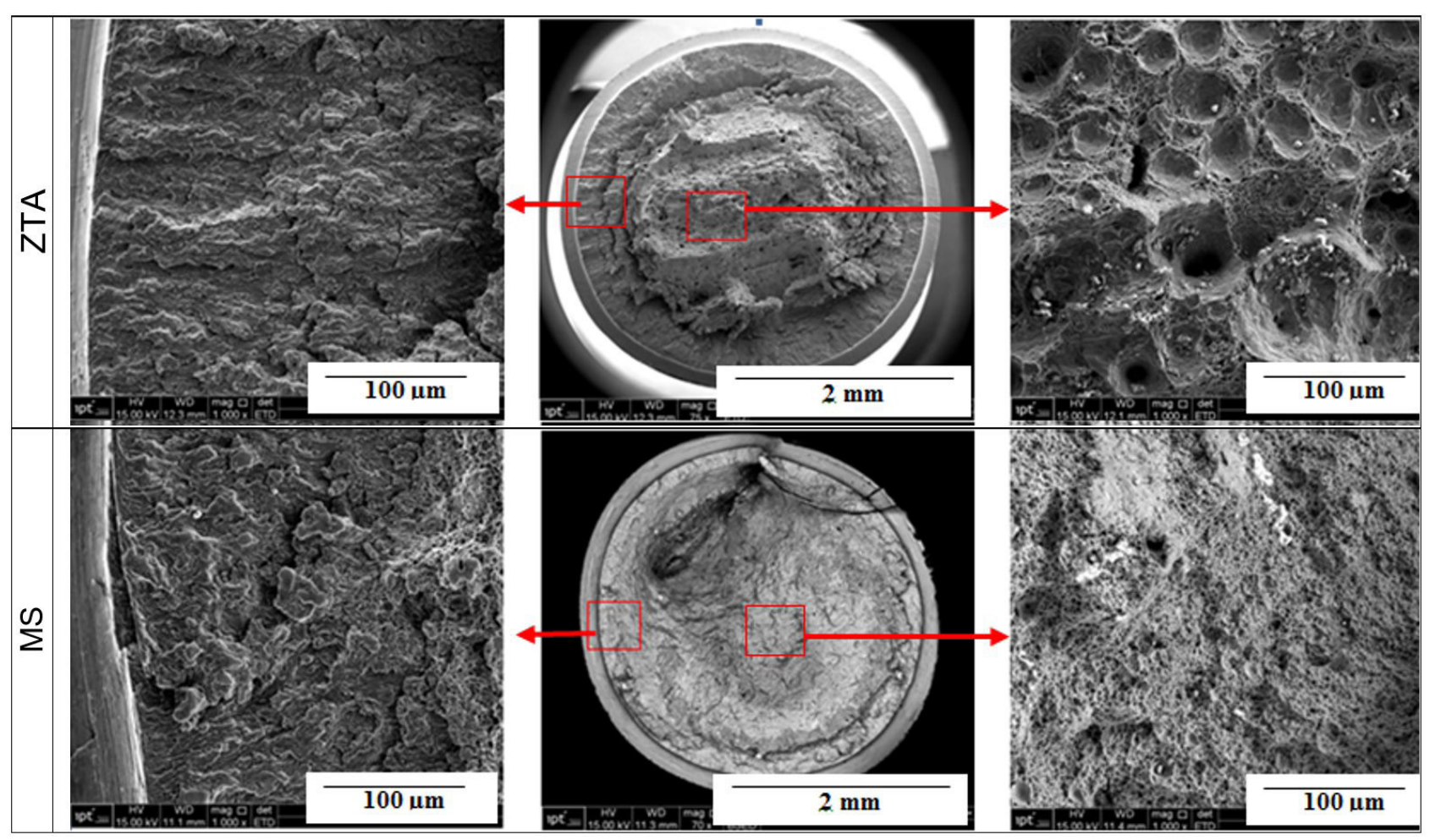

Figura 6. Superfície de fratura após ensaios de TBTD em etanol, para corpos de prova com entalhe na ZTA e no MS. 
para o exterior do tubo, num plano paralelo ao cordão de solda circunferencial. $O$ valor médio de 239 J obtido no $M B$ foi muito maior que o mínimo $(89 \mathrm{~J})$ requerido pela norma API 5L [I]. Os menores valores, correspondentes à fratura no $M S(\sim 84 \mathrm{~J})$, se devem às descontinuidades da solda, enquanto que a dispersão de resultados na ZTA está relacionada com a própria heterogeneidade da região, podendo o caminho de propagação da fratura se desviar em direção ao MS ou ao MB.

$\mathrm{Na}$ Figura 8, a imagem (a) do MB fraturado por impacto evidencia uma delaminação alongada paralelamente ao progresso da fratura e várias fissuras perpendiculares, decorrentes da anisotropia microestrutural. Ampliações maiores nas imagens (b) e (c) mostram o aspecto misto
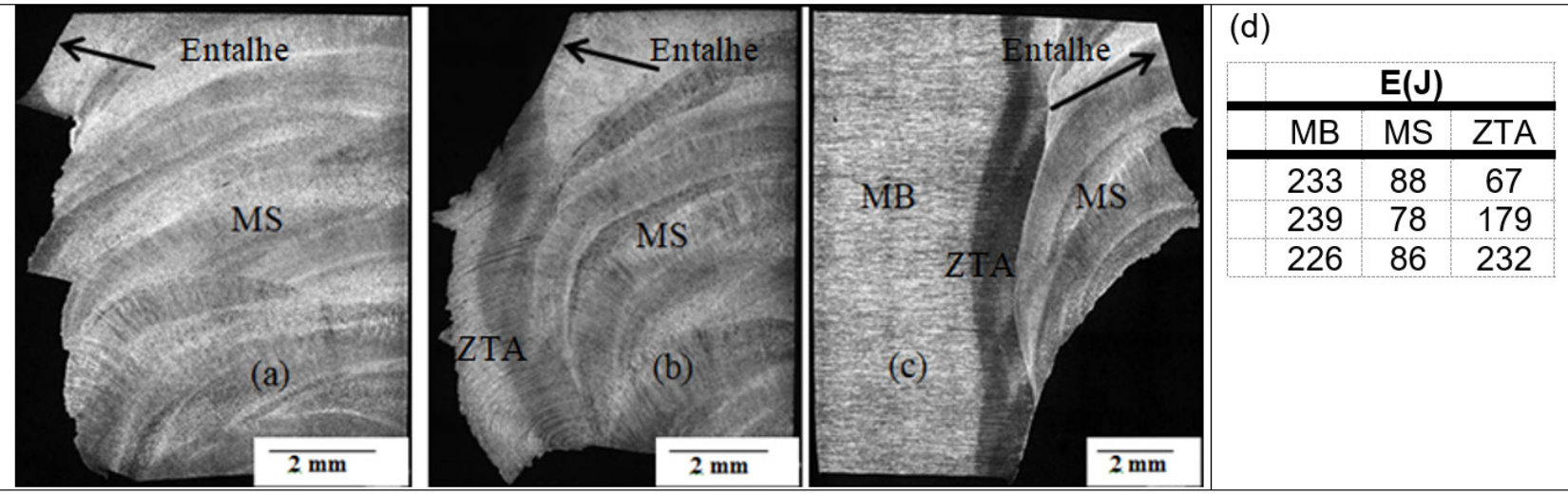

Figura 7. Macrografias indicando o caminho de propagação de fratura em ensaios de impacto Charpy com entalhe na ZTA (a,b) ou no MS (c) e Energia absorvida no impacto (d). As setas indicam a posição do entalhe.

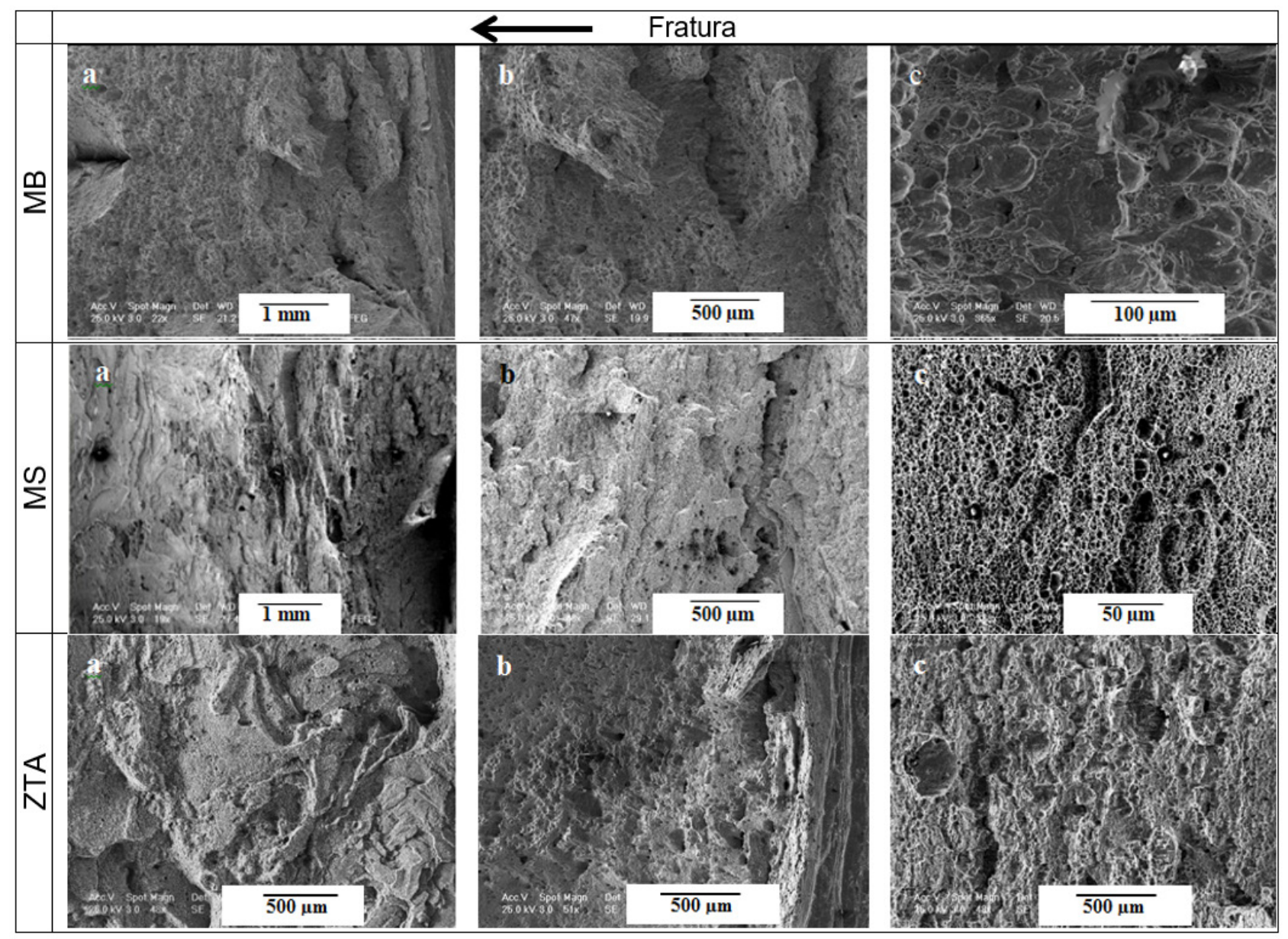

Figura 8. Imagens MEV da superfície de fratura por impacto Charpy no MB, no MS e na ZTA. A fratura progride da direita para a esquerda. 
da fratura: presença de regiões dúcteis com formação de alvéolos e regiões com trincas secundárias perpendiculares à direção da fratura com formação de facetas que parecem seguir os planos de clivagem dos grãos. Na linha referente ao MS da Figura 8, a imagem (a) evidencia uma região onde a fratura progride na interface entre dois passes de solda. $\mathrm{Na}$ imagem (b) há evidencias de fissuras e mudanças na direção de propagação da fratura (ver Figura 7). Ampliações maiores, na imagem (c), mostram a presença de alvéolos menores que aqueles do $M B$, indicando menor deformação plástica. $\mathrm{Na}$ ZTA há aspectos de clivagem controlada por tensão nas paredes das cavidades de delaminação [17-19] e também regiões com formação de alvéolos típicos de deformação plástica e fratura dúctil. A imagem (a) exemplifica uma região de aspecto frágil, onde a fratura percorreu a interface ZTA/MS (ver Figura 7a); as imagens (b) e (c) mostram regiões de fratura predominantemente dúctil onde a fratura se desviou em direção ao MB (ver Figura 7b). O caráter instável do comportamento de fratura na ZTA, explica dispersão de valores de $E$ (ver Figura 7d) nos ensaios de impacto com entalhes nesta região.

\section{DISCUSSÃO}

A microestrutura bandeada em camadas de ferrita e perlita, comum nesta classe de aços $[9,10]$, tem origem no processo de laminação a quente, na fase austenítica, associada a regiões interdendriticas com alta concentração de soluto, formadas durante o processo de solidificação [20]. Quanto à ZTA e ao MS, as microestruturas decorrem essencialmente das variáveis do processo de soldagem e se caracterizam por regióes parcialmente recristalizadas na ZTA. Já o MS é composto principalmente de ferrita acicular e fases de contorno, como ferritas proeutetóide e de Widmanstätten [II,15]. A adoção da junta do tipo "meio V" teve o intuito de facilitar o posicionamento dos entalhes de modo a propagar da fratura inteiramente na ZTA, tanto nos ensaios Charpy como nos TBTD. Mesmo assim, os sucessivos passes de enchimento produziram um gradiente microestrutural ao longo da espessura da parede do tubo, que vai interferir na resposta a esses ensaios. Perto do último passe de enchimento, o resfriamento mais rápido justifica $\circ$ aparecimento das regiões um pouco mais duras que aprecem no mapa de durezas da Figura 3. Na raiz da solda há uma região mais mole, devida ao material de solda diferente e à influência dos reaquecimentos sucessivos, mas deve-se ressaltar que nos ensaios de impacto e de TBTD a ponta dos entalhes já ficava na solda de enchimento, fora dessa região da raiz. As dispersões de dureza dentro do próprio MB (240 HV a $270 \mathrm{HV})$ são atribuídas à microestrutura bandeada de perlita distribuída em camadas ao longo da matriz ferrítica. No MS é comum encontrar que os valores da dureza sejam maiores que no $M B[12,13]$, sendo desejável que sejam próximos, o que pode ser ajustado pela escolha adequada dos parâmetros de soldagem.
Trincas e fissuramentos transversais podem ser causados por inclusões não metálicas ou por efeitos de orientações preferenciais de textura associados com alta densidade de grãos ferríticos alongados (como é o presente caso) e influem nos resultados de ensaios de tenacidade e fratura $[17,18$, 21]. Uma observação um pouco mais detalhada revelou que as cavidades de delaminação identificadas nas superfícies de fratura em tração do MB (Figura 4) ocorrem pelo modo de fratura por clivagem, sendo possível identificar tais planos nas paredes dessas cavidades, como já foi observado por outros pesquisadores [19].

Quanto à resistência à tração da junta soldada, embora tenha alcançado os limites mínimos de norma [I], ficou evidente que as descontinuidades encontradas no MS afetaram os resultados, fraturando na solda e reduzindo o alongamento final. Ressalte-se, porém, que na escala das dimensões do duto, tais descontinuidades não desqualificaram a solda.

Nos ensaios TBTD em meio etanol ficou evidente o efeito da CST, com a formação de um anel externo fragilizando a fratura tanto na ZTA quanto no MS. Efeitos similares foram observados em corpos de prova não soldados do aço API $X 65$ [22] e do aço ASTM A36 [23], sugerindo que os fatores metalúrgicos pouco afetam o processo de CST [24]. Quanto aos possíveis efeitos da composição do etanol (presença de cloretos, água, pHe e níveis de oxigênio) e dos parâmetros de controle do ensaio (taxa de deformação e geometria do $\mathrm{CP}$ ), já foi apontado, por exemplo, que a CST nos ensaios TBTD com etanol é acelerada quando se utilizam CP's com entalhe [25]; sugere-se também que a susceptibilidade à CST pode ser mitigada com um controle adequado da composição do etanol, embora haja alguma controvérsia na literatura quanto aos efeitos de cada componente [22, 23].

Entretanto, para situações que envolvam esforços cíclicos ou de impacto, seriam necessários testes específicos de mecânica da fratura [23]. Mesmo a aplicabilidade da norma NACE TMOI I I para avaliação da CST em etanol traz limitações, uma vez que esta não inclui critérios de aceitação de desempenho com base nos dados de ensaios TBTD [26]. No presente caso, os ensaios TBTD em etanol com a fratura induzida no MS sugerem que o efeito de perda de ductilidade pela presença das descontinuidades da solda pode ser potencializado pela CST, pelo menos na escala de dimensões das amostras aqui empregadas.

Por fim, ensaios de impacto Charpy com altas taxas de deformação, mostraram instabilidades no caminho da fratura na ZTA e no MS. Na primeira, a fratura é desviada para as interfaces com o MB ou com o MS. No segundo (MS), a fratura se desvia nas interfaces entre os passes de solda, reduzindo drasticamente o valor da energia absorvida no impacto. Ainda assim, os valores de E estão próximos dos limites tecnicamente admissíveis [I] e comportamentos semelhantes são encontrados na literatura $[14,16]$, mas ficou evidenciado que a junta soldada pode se constituir numa região de menor resistência à fratura por impacto. 


\section{CONCLUSÕES}

A junta soldada analisada apresentou microestruturas compatíveis com o esperado e atendeu os requisitos mínimos de norma para resistência à tração, dureza e impacto. Entretanto, ficou evidente que, especialmente na região do MS, a presença de descontinuidades afetou de forma significativa a ductilidade sob tração e a energia absorvida no impacto. Concluiu-se que a solda circunferencial usada na construção de dutos, ainda que executada conforme os procedimentos de qualificação, constitui uma região mais susceptível a falhas, especialmente na fratura por impacto. Durante os ensaios de tração com baixa taxa de deformação (TBTD) em contato com etanol (SFGE) a CST ocorreu em ambas as regióes avaliadas (ZTA e MS), produzindo um anel circunferencial de fratura essencialmente transgranular e trincas secundárias perpendiculares à superfície de fratura. Em presença de etanol as descontinuidades da solda podem potencializar a CST e acelerar o processo de fratura.

\section{REFFERÊNCIAS}

I American Petroleum Institute. API Specification 5L. Specification for Line Pipe. 45th ed. Washington: API; 2012.

2 Kane RD, Maldonado JG. Stress corrosion cracking of carbon steel in fuel grade ethanol: Review and survey. Publication 939D. Washington: American Petroleum Institute; 2003.

3 American Petroleum Institute. API Standard I I04: Welding of pipelines and related facilities. Edition 2 I st. Washington: API; 2013.

4 American Society for Testing and Materials. ASTM E384- 17: Standard Test Method for Microindentation Hardness of Materials. West Conshohocken: ASTM International; 2017.

5 American Society for Testing and Materials. ASTM E8M-16a: Standard Test Methods for Tension Testing of Metallic Materials. West Conshohocken: ASTM International; 2016.

6 NACE International. NACE Standard TM0I I I - Item No. 21255. Standard Test Method: Slow Strain Rate Test Method for Evaluation of Ethanol Stress Corrosion Cracking in Carbon Steels. Houston: NACE International; 20II.

7 American Society for Testing and Materials. ASTM D4806- I 3a: Standard Specification for Denatured Fuel Ethanol for Blending with Gasolines for Use as Automotive Spark-Ignition Engine Fuel. West Conshohocken: ASTM International; 2013.

8 American Society for Testing and Materials. ASTM E23- 18: Standard Test Methods for Notched Bar Impact Testing of Metallic Materials. West Conshohocken: ASTM International; 2018.

9 Zhao MC, Yang K, Shan YY. The effects of thermo-mechanical control process on microstructures and mechanical properties of a commercial pipeline steel. Materials Science and Engineering A. 2002;335: 14-20.

10 Zhao MC, Yang K, Xiao FR, Shan YY. Continuous cooling transformation of undeformed and deformed low carbon pipeline steels. Materials Science and Engineering A. 2003;355: I 26-I 36.

I I Francisco J.C.S. Resistência à propagação dúctil de trincas em aço API $5 \mathrm{~L} \times 70$ com teor de nióbio modificado. (tese). São Carlos: Escola de Engenharia de São Carlos, Universidade de São Paulo; 2015.

I2 Barbosa V. S. Avaliação da integridade estrutural em um tubo de aço API $5 \mathrm{~L} X 70$ através da propagação de trincas por fadiga (dissertação). Guaratinguetá: Faculdade de Engenharia, Universidade Estadual Paulista; 2014.

13 Albuquerque SF, Maciel TM, Santos MA, Bracarense AQ. Avaliação da microestrutura e propriedades mecânicas de metais de solda obtidos por processos de soldagem manual e automatizado utilizado na soldagem de aço API $5 \mathrm{~L}$ X80. Soldagem e Inspeção. 2011;16:322-332.

14 Albuquerque SF, Maciel TM, Santos MA, Lima IE. Avaliação das propriedades mecânicas de uma junta soldada de uma tubulação de aço API 5L-X60. Soldagem e Inspeção. 2003;8:30-38.

15 Hashemi SH, Mohammadyani D. Characterization of weldment hardness, impact energy and microstructure in API X65 steel. International Journal of Pressure Vessels and Piping. 20I2;98:8-I5.

16 Hashemi SH. Apportion of charpy energy in API 5L grade X70 pipeline steel. International Journal of Pressure Vessels and Piping. 2008;85:879-884.

17 Haskel HL, Pauletti E, Martins JP, Carvalho ALM. Microstructure and microtexture assessment of delamination phenomena in Charpy impact tested specimens. Materials Research. 2014; I 7: 1238-1 250.

18 Joo MS, Suh DW, Bhadeshia HKDH. Mechanical anisotropy in steels for pipelines. The Iron and Steel Institute of Japan. ISIJ International. 20|3;53:1305-13|4. 
19 Ruggieri C. Hippert E Jr. Delamination effects on fracture behaviour of a pipeline steel: a numerical investigation of 3-D crack front fields and constraint. International Journal of Pressure Vessels and Piping. 20 I5; I28: I8-35.

20 Thompson SW, Howelli PR. Factors influencing ferrite/perlite banding and origin of large pearlite nodules in a hypoeutectoid plate steel. Materials Science and Technology. 1992;8(9):777-784.

2I Fearnehough GD. Fracture propagation control in gas pipelines: a survey of relevant studies. International Journal of Pressure Vessels and Piping. 1974;2:257-282.

22 Lou X, Singh PM. Phase angle analysis for stress corrosion cracking of carbon steel in fuel-grade ethanol: Experiments and simulation. Electrochimica Acta. 201 I;56:1835-1847.

23 American Petroleum Institute. Stress corrosion cracking of carbon steel in fuel-grade ethanol: review, experience survey, filed monitoring, and laboratory testing: API Technical Report 939-D. 2nd ed. Washington: API; 2007.

24 Beavers JA, Gui F, Sridhar N. Effects of environmental and metallurgical factors on the stress corrosion cracking of carbon steel in fuel-grade ethanol. Corrosion. 20II;67(2): I-I5.

25 Bretenbach JO, Renck TS, Kwitniewski CEF, Strohaecker TR, Pimenta GS, Baptista IP et al. Evaluation of the notch influence on the stress corrosion cracking susceptibility of the API $5 L$ X70 steel in ethanol. Corrosion Science. 2104;70(9):907-9|4.

26 Kane RD. Use of NACE TMOI I I slow strain rate test for evaluation of ethanol SCC. In: NACE International Corrosion 2015 Conference \& Expo; 2015 March 15-19; Dallas, USA. Houston: NACE International; 20I5. Paper No 5945.

Recebido em: 12 Nov. 2018

Aceito em: 16 Set. 2019 